University of Nebraska - Lincoln

DigitalCommons@University of Nebraska - Lincoln

Faculty Publications from the Department of Electrical \& Computer Engineering, Department Electrical and Computer Engineering

$1-2012$

\title{
Wind Speed and Rotor Position Sensorless Control for Direct-Drive PMG Wind Turbines
}

Wei Qiao

University of Nebraska-Lincoln, wqiao@engr.unl.edu

Xu Yang

University of Nebraska-Lincoln, xu.yang@huskers.unl.edu

Xiang Gong

University of Nebraska-Lincoln, xiang.gong@huskers.unl.edu

Follow this and additional works at: https://digitalcommons.unl.edu/electricalengineeringfacpub

Part of the Electrical and Computer Engineering Commons

Qiao, Wei; Yang, Xu; and Gong, Xiang, "Wind Speed and Rotor Position Sensorless Control for Direct-Drive PMG Wind Turbines" (2012). Faculty Publications from the Department of Electrical and Computer Engineering. 187.

https://digitalcommons.unl.edu/electricalengineeringfacpub/187

This Article is brought to you for free and open access by the Electrical \& Computer Engineering, Department of at DigitalCommons@University of Nebraska - Lincoln. It has been accepted for inclusion in Faculty Publications from the Department of Electrical and Computer Engineering by an authorized administrator of DigitalCommons@University of Nebraska - Lincoln. 


\title{
Wind Speed and Rotor Position Sensorless Control for Direct-Drive PMG Wind Turbines
}

\author{
Wei Qiao, Member, IEEE, Xu Yang, Student Member, IEEE, and Xiang Gong, Student Member, IEEE
}

\begin{abstract}
This paper proposes a wind speed and rotor position sensorless control for wind turbines directly driving permanent magnetic generators (PMGs). A sliding-mode observer is designed to estimate the rotor position of the PMG by using the measured stator currents and the commanded stator voltages obtained from the control scheme of the machine-side converter of the PMG wind turbine. The rotor speed of the PMG (i.e., the turbine shaft speed) is estimated from its back electromotive force using a model adaptive reference system observer. Based on the measured output electrical power and estimated rotor speed of the PMG, the mechanical power of the turbine is estimated by taking into account the power losses of the wind turbine generator system. A back-propagation artificial neural network is then designed to estimate the wind speed in real time by using the estimated turbine shaft speed and mechanical power. The estimated wind speed is used to determine the optimal shaft speed reference for the PMG control system. Finally, a sensorless control is developed for the PMG wind turbines to continuously generate the maximum electrical power without using any wind speed or rotor position sensors. The validity of the proposed estimation and control algorithms are shown by simulation studies on a 3-kW PMG wind turbine and are further demonstrated by experimental results on a 300-W practical PMG wind turbine.
\end{abstract}

Index Terms-Artificial neural network (ANN), back electromotive force (EMF), permanent-magnetic generator (PMG), sensorless control, sliding-mode observer, wind turbine.

\section{INTRODUCTION}

$\mathbf{P}$ ERMANENT-MAGNET generators (PMGs) are commonly used in small and medium-size wind turbine systems for electrical power generation [1], [2]. Compared to the wind turbines equipped with induction generators, there are several advantages of using PMGs. First, the PMGs can provide high-efficiency and high-reliability power generation, since there is no need for external excitation and no copper losses in the rotor circuit. Second, the high-power-density PMGs are small in size, which reduces the cost and weight of the wind turbine generator (WTG) system. Moreover, the wind turbine

Manuscript received December 5, 2010; revised June 21, 2011; accepted September 24, 2011. Date of publication November 15, 2011; date of current version January 20, 2012. Paper 2010-IACC-489.R1, presented at the 2010 Industry Applications Society Annual Meeting, Houston, TX, October 3-7, and approved for publication in the IEEE TRANSACTIONSON INDUSTRY APPLICATIONS by the Industrial Automation and Control Committee of the IEEE Industry Applications Society. This work was supported by the U.S. National Science Foundation under Grant ECCS-0901218 and CAREER Award ECCS-0954938.

The authors are with the Department of Electrical Engineering, University of Nebraska-Lincoln, Lincoln, NE 68588-0511 USA (e-mail: wqiao@engr. unl.edu; xu.yang@ @uskers.unl.edu; xiang.gong @ huskers.unl.edu).

Color versions of one or more of the figures in this paper are available online at http://ieeexplore.ieee.org.

Digital Object Identifier 10.1109/TIA.2011.2175877 equipped with a direct-drive PMG removes the need of using a gearbox. According to the statistical data reported in [3], about $19.4 \%$ downtime of WTGs is caused by failures of gearboxes. Without gearboxes, the WTG systems need less maintenance and have a reduced downtime and a higher reliability.

Control, monitoring, and protection of WTGs usually require the information of wind speed and generator rotor position/ speed, which can be measured by well-calibrated mechanical sensors, such as anemometers and rotor position sensors, respectively. However, the use of these mechanical sensors increases the cost and failure rate of WTG systems. According to [3], sensor failures contribute to more than $14 \%$ of failures in WTG systems; and more than $40 \%$ of failures are related to the failure of sensors and the consequent failures of the control or electrical systems. Repairing the failed components requires additional cost and leads to a significant loss in electrical power production.

The problems incurred in using mechanical sensors can be solved through mechanical sensorless control. In [4] and [5], the wind speed was estimated based on power signal feedback, but the generator rotor position or speed was still measured for wind speed estimation and WTG control. The control systems in [6]-[8] used a hill-climb searching algorithm, which employed an incremental control action to track the maximum power point of the wind turbine. That method does not need the information of wind speed. However, it may take a long search time for that method to locate the optimal operating point. Therefore, if the wind speed changes from time to time, the WTG may operate at nonoptimal conditions frequently. In [9], the wind speed was predicted for WTG control from an autoregressive statistical model by using historical data. Most of these works still used generator rotor position/speed measurements.

In existing WTG control systems, rotor position sensors are used not only to get the shaft speed information but also to control the frequency of the power electronic converters. The previous research on rotor position sensorless control has been focused in the area of permanent magnet (PM) motor drives. For example, in [10] a sliding-mode observer was developed for rotor position sensorless control of PM synchronous motors without saliency. Reference [11] pointed out that the output voltage of the $d$-axis current regulator of the drive system would have the information of rotor position errors in a nonsalient PM synchronous motor. If a PI controller was employed to control the position errors to zero, the output of the PI controller would have the information of the rotor position.

This paper proposes a novel mechanical sensorless control for direct-drive PMG wind turbines, where the measurements 


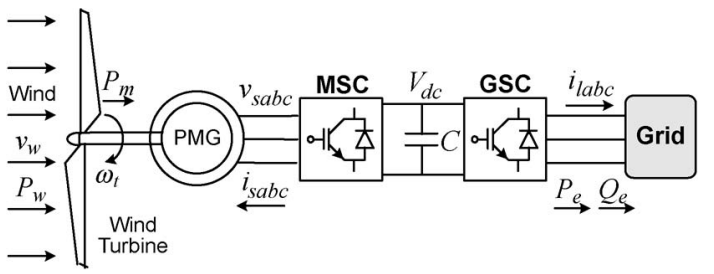

Fig. 1. Configuration of a direct-drive PMG wind turbine connected to a power grid.

are not needed for wind speed or generator rotor position. First, a sliding-mode observer is designed to estimate the back electromotive force (EMF) of the PMG, which is then used to determine the rotor position of the PMG. Second, a model adaptive reference system (MRAS) observer is designed to estimate the rotating speed of the PMG by using the estimated back EMF from the sliding-mode observer. Third, based on the measured electrical power and estimated rotor speed of the PMG, the mechanical power of the wind turbine is estimated by taking into account the power losses of the system. Fourth, the wind speed is estimated with the information of the WTG shaft speed and mechanical power by using a back-propagation artificial neural network (BPANN). The estimated wind speed is then used to determine the optimal shaft speed reference. Based on the proposed estimation algorithms, a sensorless control is developed for PMG wind turbines to continuously generate the maximum electrical power without using any wind speed or rotor position sensors.

\section{DiRECT-DRIVE PMG Wind TuRbine System}

The configuration of a PMG wind turbine is shown in Fig. 1, where the wind turbine is connected to the PMG directly. The electrical power generated by the PMG is transmitted to a power grid and/or supplied to a load via a variable-frequency converter, which consists of a machine-side converter (MSC) and a grid-side converter (GSC).

\section{A. Wind Turbine Aerodynamic Model}

The mechanical power that a wind turbine extracts from the wind is given by

$$
P_{m}=\frac{1}{2} \rho A_{r} v_{w}^{3} C_{p}(\lambda)=f\left(v_{w}, \omega_{t}\right)
$$

where $\rho$ is the air density; $A_{r}$ is the area swept by the blades; $v_{w}$ is the wind speed; $C_{P}$ is the turbine power coefficient; $\omega_{t}$ is the turbine shaft speed; and $\lambda$ is the tip-speed ratio, which is defined by

$$
\lambda=\frac{\omega_{t} R}{v_{w}}
$$

where $R$ is the radius of the wind turbine rotor plane. In this paper, $C_{P}$ is given by [12]

$$
C_{p}=\frac{1}{2}(\lambda-5.6) \exp (-0.17 \lambda)
$$

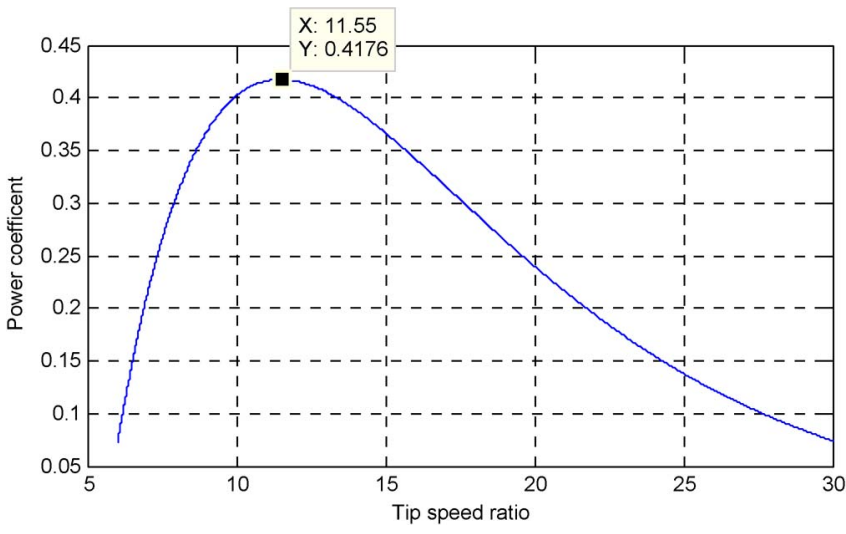

Fig. 2. $C_{P}-\lambda$ curve of the wind turbine.

Fig. 2 shows the relationship between $C_{P}$ and $\lambda$ given by (3). The maximum value of $C_{P}$ is reached when $\lambda$ is approximately 11.55 .

\section{B. Modeling of the PMG}

The dynamic equations of a three-phase PMG without saliency can be written in a synchronously rotating $d q$ reference frame as

$$
\begin{aligned}
& v_{s q}=R_{s} i_{s q}+\frac{d \psi_{q}}{d t}+\omega_{r} \psi_{d} \\
& v_{s d}=R_{s} i_{s d}+\frac{d \psi_{d}}{d t}-\omega_{r} \psi_{q}
\end{aligned}
$$

where $v_{s q}$ and $v_{s d}$ are the $q$-axis and $d$-axis stator terminal voltages, respectively; $i_{s q}$ and $i_{s d}$ are the $q$-axis and $d$-axis stator currents, respectively; $R_{s}$ is the resistance of the stator windings; $\omega_{r}\left(=p \omega_{t}\right)$ is the electrical angular velocity of the rotor, and $p$ is the number of pole pairs of the PMG; and $\psi_{q}$ and $\psi_{d}$ are the $q$-axis and $d$-axis flux linkages of the PMG, respectively, given by

$$
\begin{aligned}
& \psi_{q}=L_{q} i_{s q} \\
& \psi_{d}=L_{d} i_{s d}+\psi_{m}
\end{aligned}
$$

where $\psi_{m}$ is the flux linkage generated by the PM. The electromagnetic torque can be calculated by

$$
T_{e}=\frac{3}{2} \frac{p}{2}\left(\psi_{m} i_{s q}+\left(L_{d}-L_{q}\right) i_{s d} i_{s q}\right) .
$$

For a nonsalient PMG,

$$
T_{e}=\frac{3}{2} \frac{p}{2} \psi_{m} i_{s q}
$$

where $L_{q}$ and $L_{d}$ are the $q$-axis and $d$-axis inductances of the PMG, respectively. The output electrical power can be calculated by

$$
P_{e}=\frac{3}{2}\left(v_{s d} i_{s d}+v_{s q} i_{s q}\right)
$$




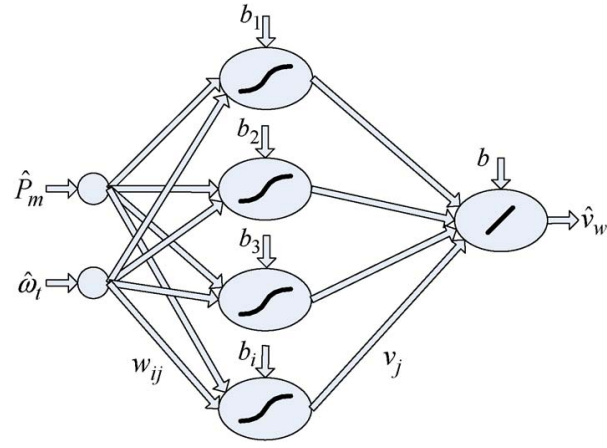

Fig. 3. BPANN-based wind speed estimation algorithm.

\section{Modeling of the Shaft System}

As the wind turbine is connected to the PMG directly, the shaft system of the WTG can be represented by a one-mass model. The motion equation is then given by

$$
2 H \frac{d \omega_{t}}{d t}=\frac{P_{m}}{\omega_{t}}-\frac{P_{e}}{\omega_{t}}-D \omega_{t}
$$

where $2 H$ is the total inertia constant of the WTG; $P_{e}$ is the electrical power of the PMG; and $D$ is the damping coefficient.

\section{ReAL-Time Wind SpeEd Estimation}

If the information of the turbine mechanical power and shaft speed is known, the wind speed can be calculated from the nonlinear inverse function of (1). Artificial neural networks (ANNs) are an effective tool for nonlinear mapping and are used in this paper for wind speed estimation.

In the proposed algorithm, a three-layer BPANN is used to provide a static nonlinear inverse mapping of the wind turbine aerodynamic model (1) to estimate the wind speed $v_{w}$, provided that the values of $P_{m}$ and $\omega_{t}$ are known. In this paper, $P_{m}$ and $\omega_{t}$ are both estimated instead of being measured by sensors. As shown in Fig. 3, $\hat{v}_{w}, \hat{P}_{m}$, and $\hat{\omega}_{t}$ are the estimated values of $v_{w}$, $P_{m}$, and $\omega_{t}$, respectively.

The overall input-output mapping of the BPANN is

$$
\hat{v}_{w}=b+\sum_{j=1}^{h} v_{j} \operatorname{tansig}\left(w_{1 j} \hat{P}_{m}+w_{2 j} \hat{\omega}_{t}+b_{j}\right)
$$

where $h$ is the number of neurons in the hidden layer; $w_{1 j}$ and $w_{2 j}$ are the weights between the input and the $j$ th neuron in the hidden layer; $v_{j}$ is the weight between the $j$ th neuron in the hidden layer and the output; $b_{j}$ and $b$ are the bias terms of the hidden layer and the output layer, respectively; "tansig" is the hyperbolic tangent sigmoid transfer function, defined by

$$
\tan \operatorname{sig}(x)=\frac{2}{1+e^{-2 x}}-1
$$

The parameters of the BPANN, including the weights, bias terms, and the number of neurons in the hidden layer, are determined by using a set of training data generated from the wind turbine aerodynamic model or experiments. This data set covers the whole operating range of the WTG. The BPANN is trained by using the training data set until an acceptable error

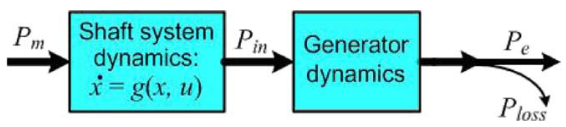

Fig. 4. Power flow of the WTG system.

is reached. Then, the parameters of the BPANN are fixed and used for real-time wind speed estimation.

\section{Real-Time Shaft Mechanical Power Estimation}

The wind speed estimation algorithm in Section III needs the information of the turbine mechanical power. In a WTG system, the conversion from turbine mechanical power to generator electrical power can be illustrated by the process in Fig. 4. The mechanical power $P_{m}$ of the wind turbine is transmitted to the PMG through the shaft, whose dynamics are represented by the differential equation (11). The PMG converts mechanical power $P_{m}$ into electrical power $P_{e}$. The power losses, $P_{\text {loss }}$, of the PMG is considered in the model, where $P_{i n}=P_{e}+P_{\text {loss }}$.

The $P_{\text {loss }}$ consists of four parts, i.e., the copper loss in the stator windings, the core loss, the mechanical loss, and the stray load loss. The copper loss $P_{\text {copper }}$ is given by

$$
P_{\text {copper }}=\frac{3}{2}\left(i_{s q}^{2} R_{s}+i_{s d}^{2} R_{s}\right) .
$$

The core loss of the PMG depends on the flux linkage and the rotor speed [13]. The mechanical loss is assumed to be $1.0 \%$ of the electrical power $P_{e}$ [14]. The stray load loss is also assumed to be $1.0 \%$ of the electrical power $P_{e}$ [15].

By using the measured electrical power $P_{e}$ and the estimated value of the power losses, $P_{\text {loss }}$, the turbine mechanical power $P_{m}$ can be estimated with the model (11) of the shaft system. In the real-time estimation, (11) can be rewritten in the discretetime format as follows:

$\hat{P}_{m}(t)=\left(\frac{2 H}{\Delta t}+D\right) \hat{\omega}_{t}^{2}(t)-\frac{2 H}{\Delta t} \hat{\omega}_{t}(t) \hat{\omega}_{t}(t-1)+P_{e}(t)+P_{\text {loss }}(t)$.

Equation (15) shows that the turbine mechanical power can be estimated from the electrical power $P_{e}$ and the power losses $P_{\text {loss }}$ if the turbine shaft speed is known.

\section{ReAl-Time PMG Rotor Position And Turbine SHAFT SPEED ESTIMATION}

The information of the PMG rotor position $\theta_{r}$ and the turbine shaft speed $\omega_{t}$ is needed for wind speed estimation and system control. In this paper, a sliding-mode observer is designed to estimate the rotor position based on the work in [10], [16]. A back EMF-based MRAS observer is designed to estimate the turbine shaft speed.

\section{A. Rotor Position Estimation}

The dynamic equations of a nonsalient PMG in the stationary reference frame can be expressed as

$$
\dot{i_{\alpha \beta}}=A \cdot i_{\alpha \beta}+B \cdot\left(v_{\alpha \beta}-e_{\alpha \beta}\right)
$$




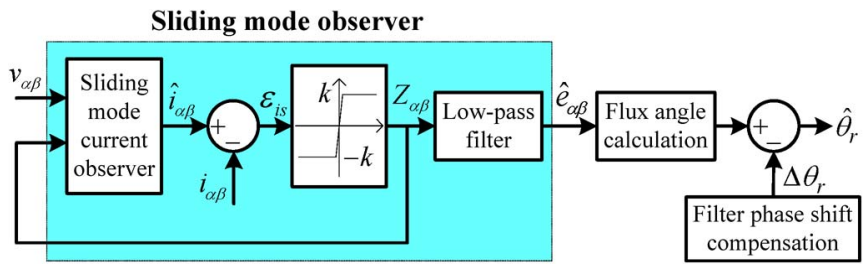

Fig. 5. Block diagram of the sliding-mode observer-based PMG rotor position estimation algorithm.

where $v_{\alpha \beta}, i_{\alpha \beta}$, and $e_{\alpha \beta}$ are the stator voltages and currents and the back EMF in the stationary reference frame; and

$$
\begin{aligned}
A & =\left[\begin{array}{cc}
\frac{-R_{s}}{L_{s}} & 0 \\
0 & \frac{-R_{s}}{L_{s}}
\end{array}\right] \quad B=\left[\begin{array}{cc}
\frac{1}{L_{s}} & 0 \\
0 & \frac{1}{L_{s}}
\end{array}\right] \\
i_{\alpha \beta} & =\left[\begin{array}{ll}
i_{\alpha} & i_{\beta}
\end{array}\right]^{T} \quad v_{\alpha \beta}=\left[\begin{array}{ll}
v_{\alpha} & v_{\beta}
\end{array}\right]^{T} \\
e_{\alpha \beta} & =\left[\begin{array}{c}
e_{\alpha} \\
e_{\beta}
\end{array}\right]=K_{e} \cdot \omega_{r} \cdot\left[\begin{array}{c}
-\sin \left(\theta_{r}\right) \\
\cos \left(\theta_{r}\right)
\end{array}\right]
\end{aligned}
$$

where $L_{s}$ is the inductance of the stator windings, and $K_{e}$ is a back EMF constant. Then, the sliding-mode observer is designed as follows:

$$
\begin{aligned}
& \dot{\hat{i}}_{\alpha \beta}=A \cdot \widehat{i}_{\alpha \beta}+B \cdot v_{\alpha \beta}+k \operatorname{sgn}\left(\widehat{i}_{\alpha \beta}-i_{\alpha \beta}\right) \\
& Z_{\alpha \beta}=k \operatorname{sgn}\left(\varepsilon_{i s}\right)=k \operatorname{sgn}\left(\widehat{i}_{\alpha \beta}-i_{\alpha \beta}\right)
\end{aligned}
$$

where $\hat{i}_{\alpha \beta}$ is the estimated value of $i_{\alpha \beta} ; Z_{\alpha \beta}$ is the switching signal; $\operatorname{sgn}(\cdot)$ is the sign function; $k$ is the switching gain of the observer.

Fig. 5 shows the block diagram of the observer, where $\hat{e}_{\alpha \beta}$ is the estimated value of the back EMF; and $\hat{\theta}_{r}$ is the estimated rotor position. To ensure the convergence of the sliding-mode observer, $k$ should be selected such that $\varepsilon_{i s} \cdot \dot{\varepsilon}_{i s}^{T}<0$. The estimated back EMF is obtained by a low-pass filter from the switching signal $\mathrm{Z}_{\alpha \beta}$

$$
\left\{\begin{array}{l}
\hat{e}_{\alpha}=\frac{\omega_{\text {cutoff }}}{s+\omega_{\text {cuttoff }}} Z_{\alpha} \\
\hat{e}_{\beta}=\frac{\omega_{\text {cutoff }}}{s+\omega_{\text {cutoff }}} Z_{\beta}
\end{array} .\right.
$$

The rotor position is then obtained as

$$
\widehat{\theta}_{r}=-\tan ^{-1}\left(\frac{\hat{e}_{\alpha}}{\hat{e}_{\beta}}\right) .
$$

The low-pass filter is designed to have a variable cut-off frequency $\omega_{\text {cutoff }}$ according to the rotor speed. The phase angle delay caused by the filter is

$$
\Delta \theta_{r}=\tan ^{-1}\left(\frac{\omega}{\omega_{\text {cutoff }}}\right)
$$

The delayed angle is compensated for the estimation of the rotor angle.

\section{B. Turbine Shaft Speed Estimation}

The turbine shaft speed can be simply calculated from the derivative of the rotor angle. However, in this paper, the turbine

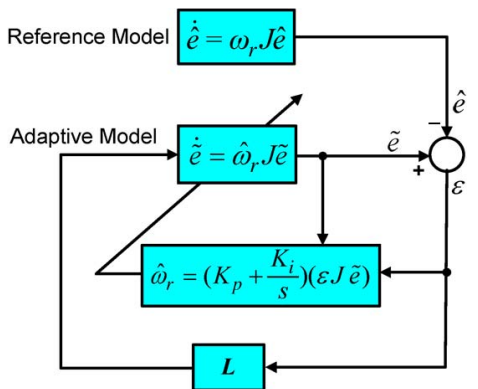

Fig. 6. Back EMF-based MRAS PMG rotor speed observer.

shaft speed is obtained from a back EMF-based MRAS observer [17] shown in Fig. 6, which has a better performance than the rotor angle derivative-based method. According to (16), if the PMG rotor speed changes slowly, i.e., $\dot{\omega}_{r} \approx 0$, the induced back EMF can be expressed as

$$
\dot{\hat{e}}_{\alpha}=-\omega_{r} \cdot \hat{e}_{\beta} \text { and } \dot{\hat{e}}_{\beta}=\omega_{r} \cdot \hat{e}_{\alpha}
$$

where $\hat{e}_{\alpha}$ and $\hat{e}_{\beta}$ are the back-EMF components estimated from the sliding-mode observer in Fig. 5. Equation (22) is then used as the reference model for the MRAS observer. The adaptive model [18] is designed as

$$
\left\{\begin{array}{l}
\dot{\tilde{e}}_{\alpha}=-\tilde{\omega}_{r} \cdot \hat{e}_{\beta}-L \cdot\left(\tilde{e}_{\alpha}-\hat{e}_{\alpha}\right) \\
\dot{\tilde{e}}_{\beta}=\tilde{\omega}_{r} \cdot \hat{e}_{\alpha}-L \cdot\left(\tilde{e}_{\beta}-\hat{e}_{\beta}\right)
\end{array}\right.
$$

where $L$ is a constant gain; $\tilde{e}_{\alpha}$ and $\tilde{e}_{\beta}$ are the induced backEMF components from the adaptive model. The adaptation mechanism for the MRAS observed is derived by using the hyper stability criteria [19] as follows:

$$
\hat{\omega}_{r}=\left(k_{p}+\frac{k_{i}}{s}\right)\left[\left(\tilde{e}_{\alpha}-\hat{e}_{\alpha}\right) \cdot \tilde{e}_{\beta}-\left(\tilde{e}_{\beta}-\hat{e}_{\beta}\right) \cdot \tilde{e}_{\alpha}\right]
$$

where $\hat{\omega}_{r}$ is the estimated rotor speed. The back EMFs used in the MRAS observer are normalized as follows:

$$
e=\frac{1}{\sqrt{e_{\alpha}^{2}+e_{\beta}^{2}}}\left[\begin{array}{l}
e_{\alpha} \\
e_{\beta}
\end{array}\right]
$$

where $e$ stands for $\hat{e}$ or $\tilde{e}$. In Fig. 6, $J=\left[\begin{array}{cc}0 & -1 \\ 1 & 0\end{array}\right]$. The turbine shaft speed $\omega_{t}$ can be obtained from $\hat{\omega}_{r}$ directly.

\section{Sensorless Control for PMG Wind Turbines}

In the proposed estimation algorithms, both the wind speed and the PMG rotor position and speed are estimated from the measured stator currents $i_{s a b c}$ and the commanded stator voltages $v_{s a b c}^{*}$ obtained from the MSC control scheme. The estimated rotor position, turbine shaft speed, and wind speed are integrated into the control system, leading to a sensorless control for the PMG wind turbine, as shown in Fig. 7. The overall control system consists of two parts: control of the MSC and control of the GSC. The GSC control keeps the dc-link voltage constant and regulates the reactive power or the magnitude of the voltage at the grid connection point of the PMG. 


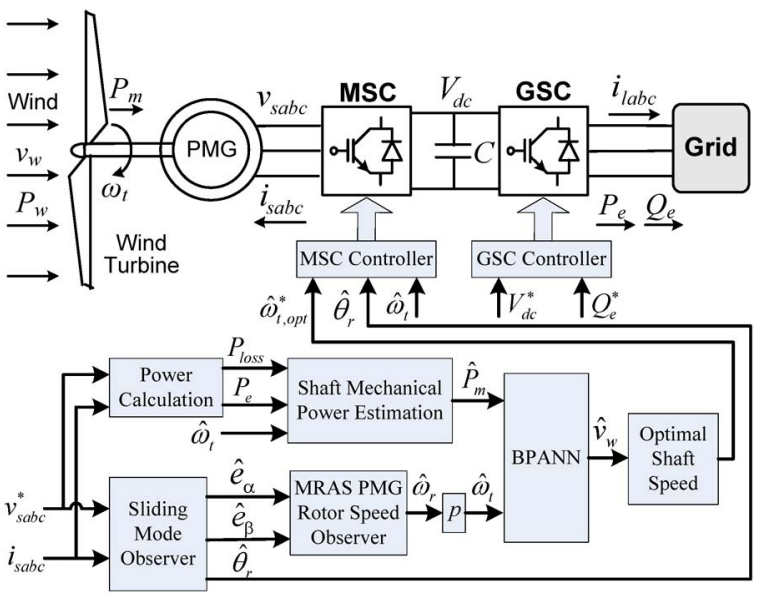

Fig. 7. Proposed sensorless control for the PMG wind turbine.

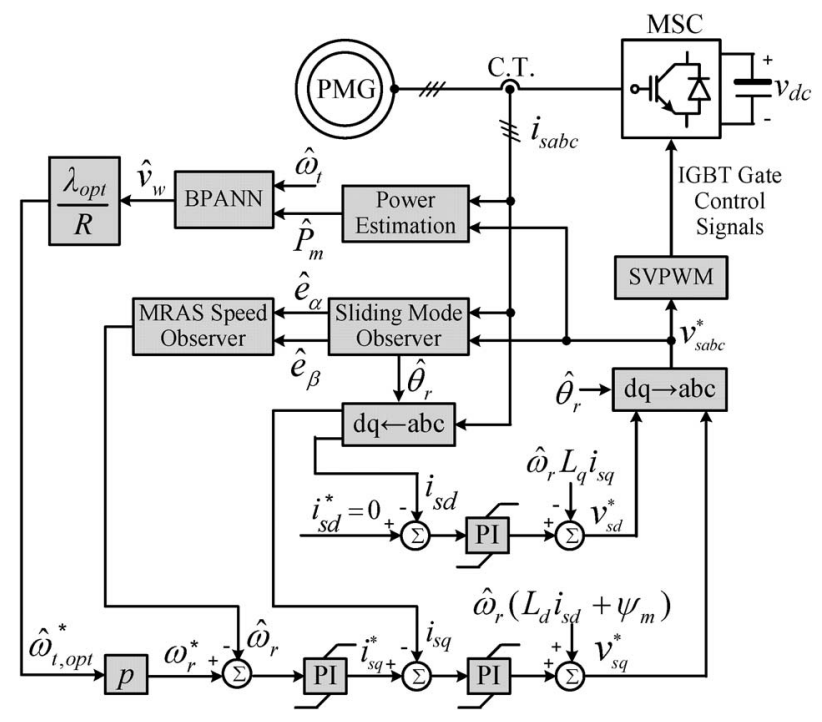

Fig. 8. Overall control scheme of the MSC.

The estimated rotor position $\hat{\theta}_{r}$ is used in the MSC control system to correctly transform the three-phase stator voltages and currents into the rotor reference frame. The overall MSC control scheme consists of two loops, as shown in Fig. 8. The inner-loop PI controllers regulate the $d$-axis and $q$-axis stator currents of the PMG according to the models of the PMG described by (4) and (5). The outer-loop speed control tracks the optimal shaft speed reference to generate the maximum power from the WTG. In this paper, the estimated wind speed is used to generate the optimal shaft speed reference, given by

$$
\omega_{t, \mathrm{opt}}^{*}=\frac{\lambda_{\mathrm{opt}} \hat{v}_{w}}{R}
$$

where $\lambda_{\text {opt }}$ is the optimal tip-speed ratio. The maximum torque per ampere is obtained by setting $i_{s d}=0$ [11].

The proposed back EMF-based rotor position and speed estimation algorithms will have satisfactory performance for the PMG operating above a certain speed, e.g., above $30 \%$ of the rated rotor speed. Typically, it is difficult to do sensorless control for the PMG at low-speed operation using back EMF due to low signal-to-noise ratio. In this case, the MSC can be

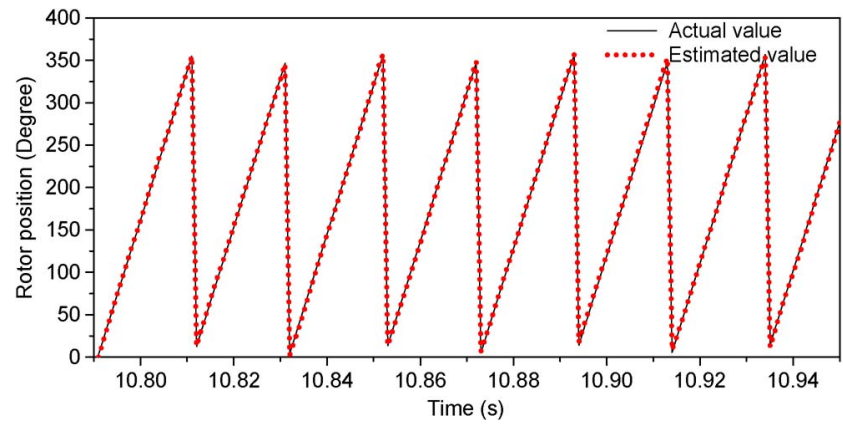

Fig. 9. Rotor position estimation results.

controlled to regulate directly the active and reactive powers of the PMG. The active and reactive powers can be calculated from the measured ac (stator) currents and commanded ac voltages of the MSC. The active power reference can be obtained from a hill-climb search algorithm [6] without the need of wind speed information; while the reactive power reference can be set to zero. The active and reactive powers are then compared with their references to generate the commanded ac voltages of the MSC without using stator current regulation. Consequently, the overall control scheme does not need the information of the rotor position or speed. Nevertheless, the power generated by a WTG is a cubic function of wind speed, thereby a cubic function of the PMG rotor speed when the WTG is operated in the maximum power point tracking mode. At low wind speeds where the PMG is operated at low speeds, e.g., below 30\% of the rated speed, the power generated by the WTG is lower than $3 \%$ of the rated power. Therefore, it is more important to investigate the sensorless control for the PMG wind turbine operating in the medium- and high-speed range where the WTG generates a significant amount of power. The issues of sensorless control for direct-drive PMG wind turbines at lowspeed operation will be investigated in the future work.

\section{Simulation Results}

Simulation studies are carried out in PSCAD to validate the proposed real-time wind speed and rotor position estimation algorithms and sensorless control for a 3-kW PMG wind turbine. The WTG system has the following parameters. For the wind turbine: the radius of the rotor plane is $R=2 \mathrm{~m}$; the air density is $\rho=1.15 \mathrm{~kg} / \mathrm{m}^{3} ; \lambda_{\text {opt }}=11.55$; the $C_{p}(\lambda)$ curve is shown in Fig. 2. For the PMG: the rated power is $3 \mathrm{~kW}$, $R_{s}=0.2499 \mathrm{ohms} ; L_{d}=34.3 \mathrm{mH} ; L_{q}=34.3 \mathrm{mH}$; the flux linkage $\psi_{m}=1.0 \mathrm{~V} \cdot \mathrm{s}$; the number of pole pairs is $p=7$; and the moment of inertia is $J=1 \mathrm{~kg} \cdot \mathrm{m}^{2}$.

During the simulation, the wind speed varies in the range of $\pm 3 \mathrm{~m} / \mathrm{s}$ around the mean value of $8 \mathrm{~m} / \mathrm{s}$. Figs. 9-13 compare the actual and estimated values of the rotor position, turbine shaft speed, shaft mechanical power, and wind speed. The results show that the proposed algorithms accurately estimate these quantities, which are used for real-time control of the PMG and converters. As shown in Fig. 13, the turbine shaft speed is controlled to track its reference with good precision by using the estimated rotor position and shaft speed. The resulting tipspeed ratio is shown in Fig. 14. The tip-speed ratio varies in a relatively small range around the optimal tip-speed ratio 


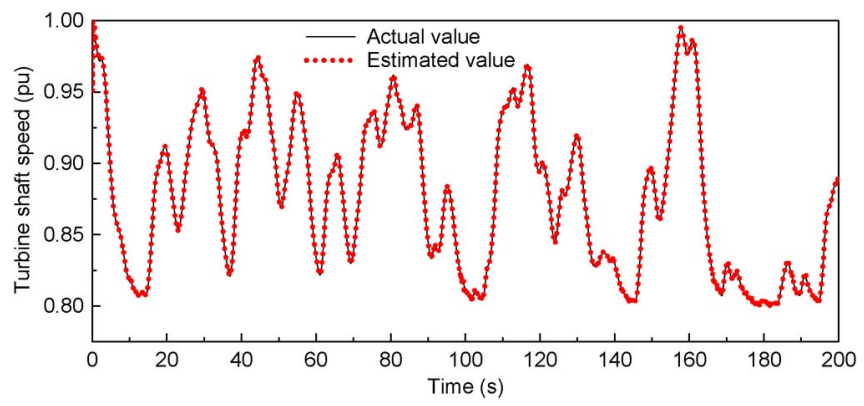

Fig. 10. Shaft speed estimation results.

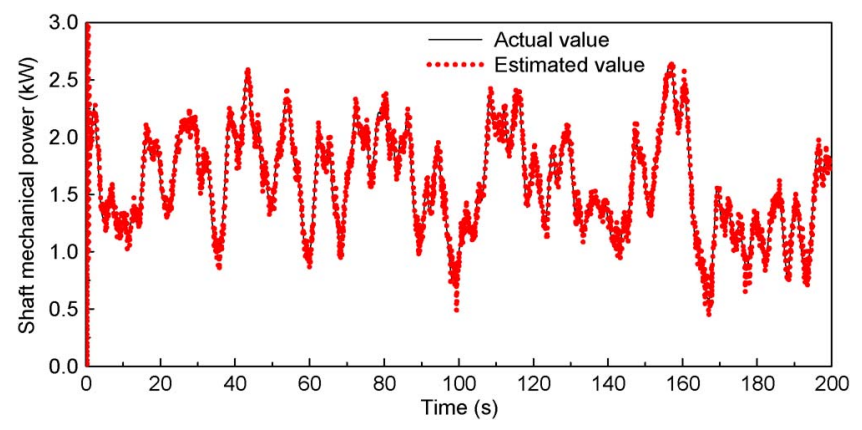

Fig. 11. Shaft mechanical power estimation results.

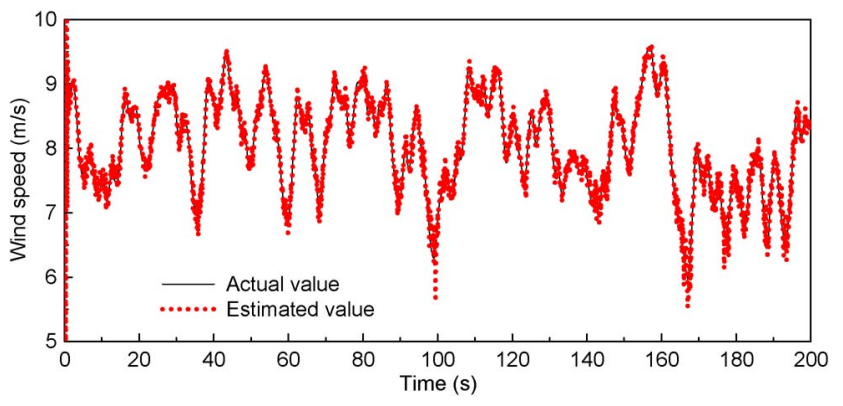

Fig. 12. Wind speed estimation results.

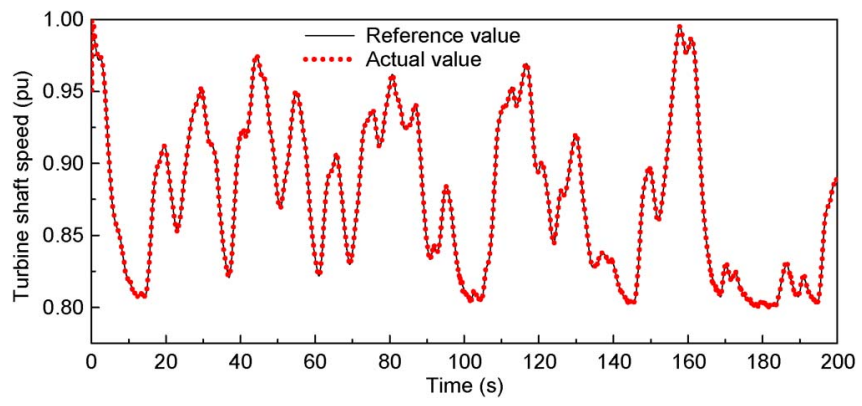

Fig. 13. Shaft speed tracking results.

of 11.55. The errors between the actual and optimal tip-speed ratios are caused by fast wind speed variations and relatively slow responses of the WTG system. This result demonstrates that the WTG is correctly controlled to generate the maximum power by using the estimated wind speed.

\section{EXPERIMENTAL RESULTS}

A 300-W PMG used in a practical direct-drive PMG wind turbine was set up to validate the proposed rotor position and

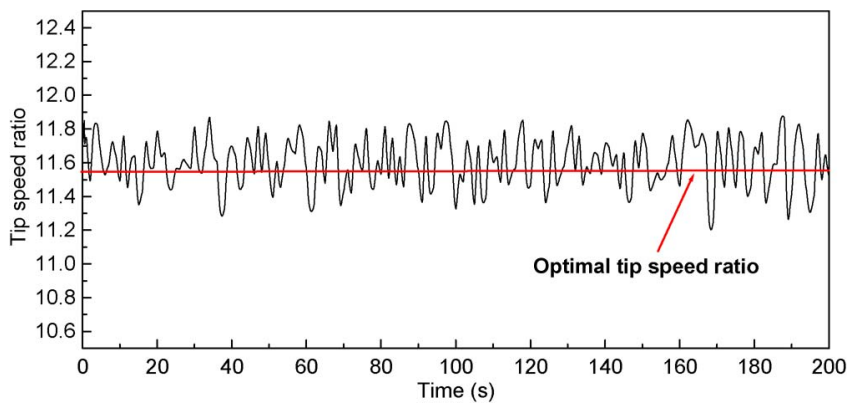

Fig. 14. Actual and optimal tip-speed ratios.

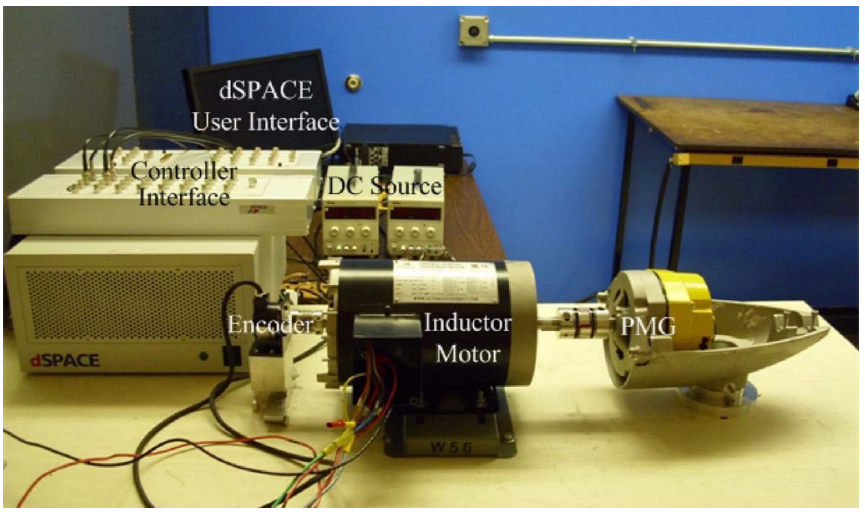

Fig. 15. Experimental setup for a 300-W PMG system.

speed estimation algorithms. Fig. 15 shows the experimental setup. The PMG was driven by an adjustable-speed induction motor drive system, which emulated the dynamics of the wind turbine. The power generated by the PMG wind turbine was consumed by a three-phase resistive load. An ARS20 absolute encoder was used to measure the PMG rotor position in real time. A sensor board acquired the stator voltages and currents of the PMG, which were used by the position and speed estimation algorithms implemented in a dSPACE system. Some typical results are presented as follows.

The rotating speed of the induction motor in Fig. 15 was changed with a $100 \mathrm{RPM} / \mathrm{s}$ ramp from $300 \mathrm{RPM}$ to the rated speed of $850 \mathrm{RPM}$ at the fifth second and back to $300 \mathrm{RPM}$ at the 21st second. By using the measured PMG stator voltages and currents, the PMG rotor speed was accurately estimated by using the proposed method, as shown in Fig. 16. Fig. 17 shows that the rotor speed estimation errors are less than 2 RPM at steady states and less than 6 RPM during the transient states of ramp changes.

Fig. 18 compares the estimated rotor position and the real rotor position measured by the encoder during the $100 \mathrm{RPM} / \mathrm{s}$ ramp changes in the rotor speed. The results show that the rotor position was accurately estimated by using the proposed method. Fig. 19 shows that the rotor position estimation errors are within $[-5,5]$ degrees during the 30 -s experiment. The ramp change transient has little effect on the performance of rotor position estimation. However, the rotor position estimation algorithm is more accurate at high rotating speeds (e.g., 850 RPM) than at low rotating speeds (e.g., 300 RPM).

The $300-\mathrm{W}$ direct-drive PMG wind turbine was tested in a wind tunnel to further validate the rotor position and speed 


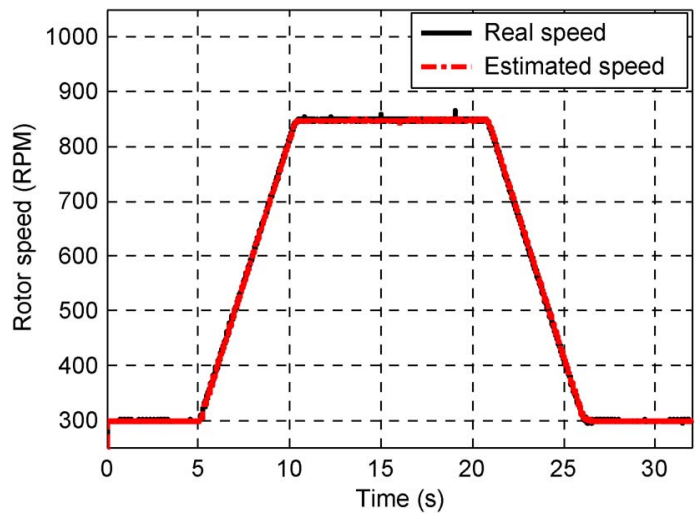

Fig. 16. Rotor speed estimation during $100 \mathrm{RPM} / \mathrm{s}$ ramp changes in rotor speed.

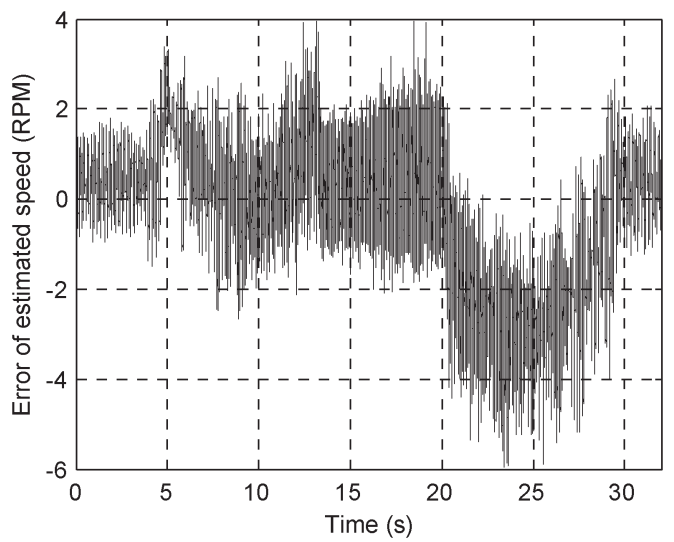

Fig. 17. Rotor speed estimation errors.

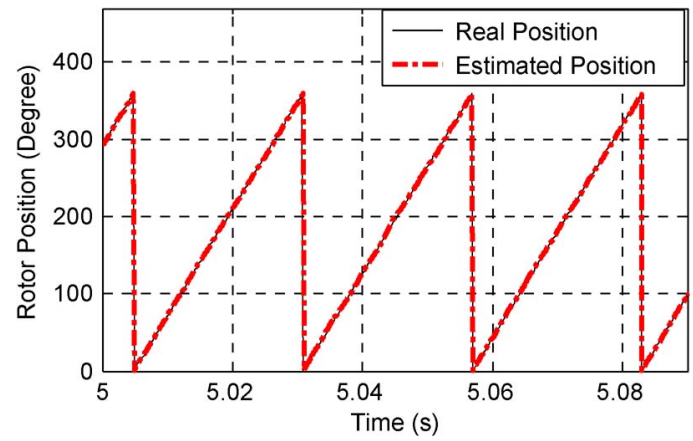

Fig. 18. Rotor position estimation during $100 \mathrm{RPM} / \mathrm{s}$ ramp changes in rotor speed.

estimation algorithms in an operational environment. Fig. 20 shows the experimental setup. The wind tunnel has the dimensions of $6.5 \mathrm{~m} \times 2.5 \mathrm{~m} \times 2.5 \mathrm{~m}$. Controllable airflows in the wind tunnel were generated by a fan of a 2.15 -meter diameter, driven by a $60-\mathrm{HP}$ adjustable-speed induction motor drive. Again, the power generated by the PMG wind turbine was consumed by a three-phase resistive load. A sensor board acquired the stator voltages and currents of the PMG, which were used by the position and speed estimation algorithms implemented in a dSPACE system.

During the experiment the rotating speed of the fan was randomly changed to generate variable wind speed in the wind tunnel. Consequently, the rotating speed of the PMG wind

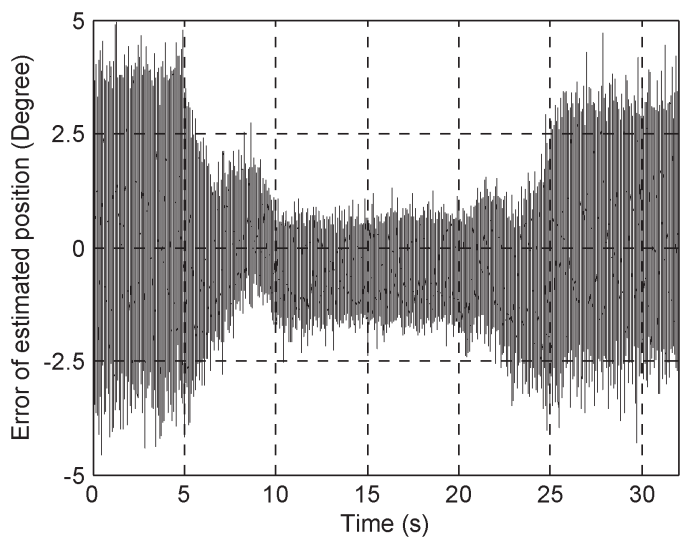

Fig. 19. Rotor position estimation errors.

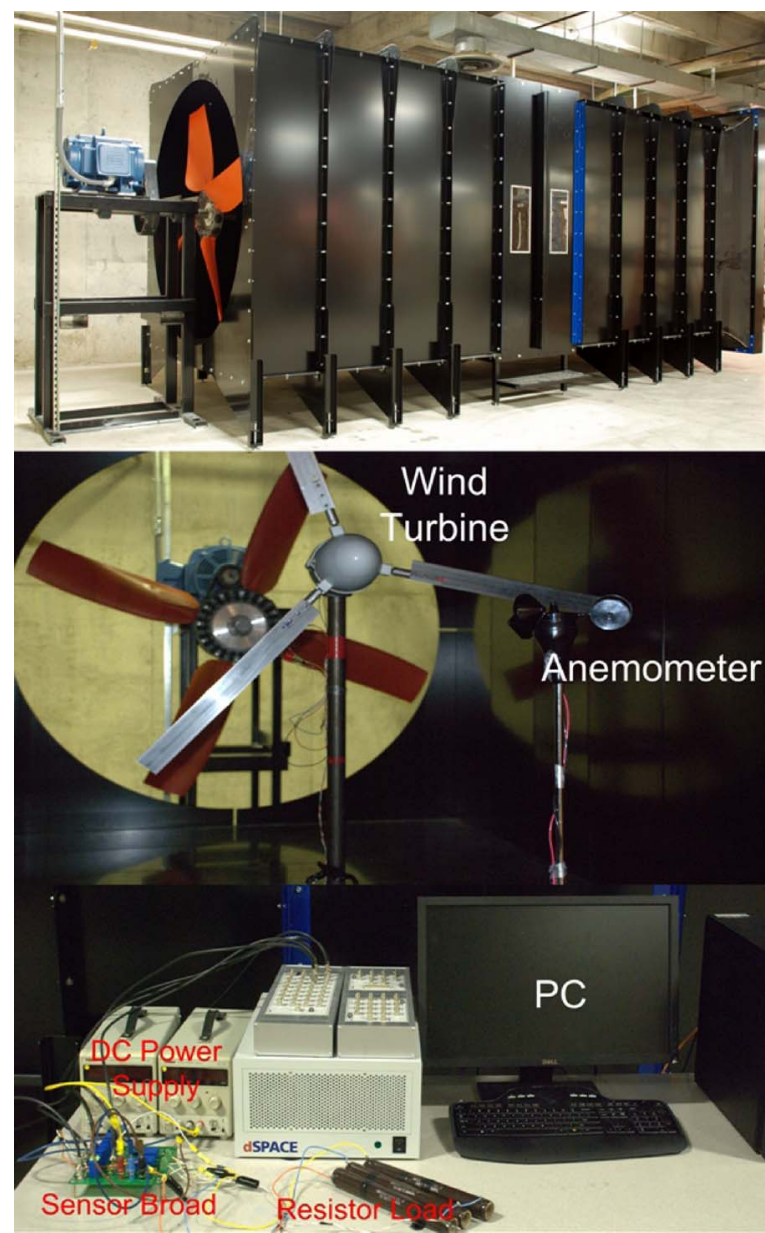

Fig. 20. Experimental setup for a 300-W PMG wind turbine operating in a wind tunnel.

turbine varied randomly in a range of [300, 850] RPM. Figs. 21 and 22 show that the proposed method estimated the PMG rotor speed with good precision. Fig. 23 compares the estimated rotor position and the real rotor position. The estimation errors are almost in the range of $[-3,3]$ degrees during the 100 -second experiment, as shown in Fig. 24. These results show that the proposed methods are effective for real-time rotor position and speed estimation during variable wind speed conditions. 


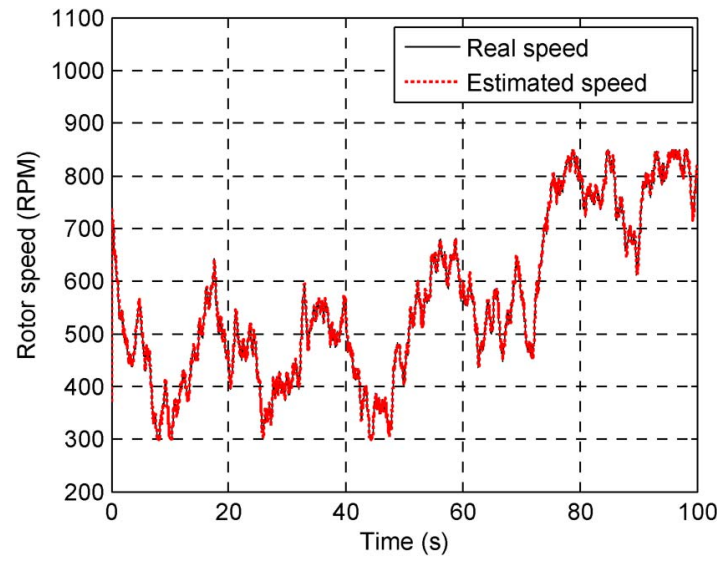

Fig. 21. Rotor speed estimation during variable wind speed operation.

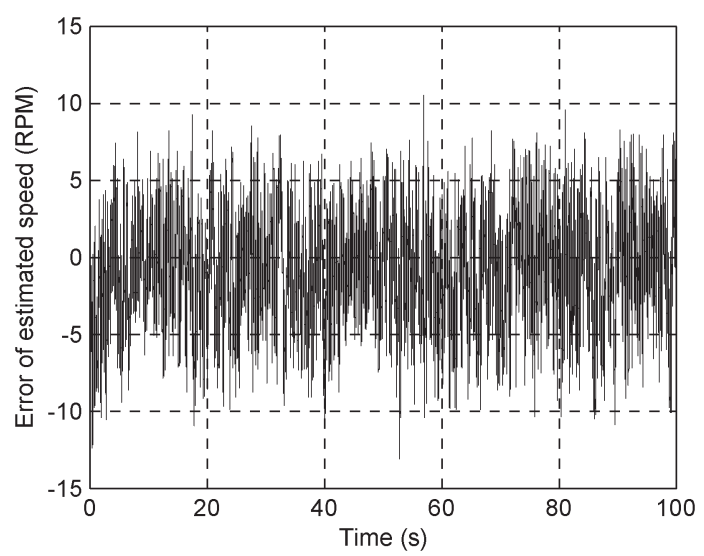

Fig. 22. Rotor speed estimation errors.

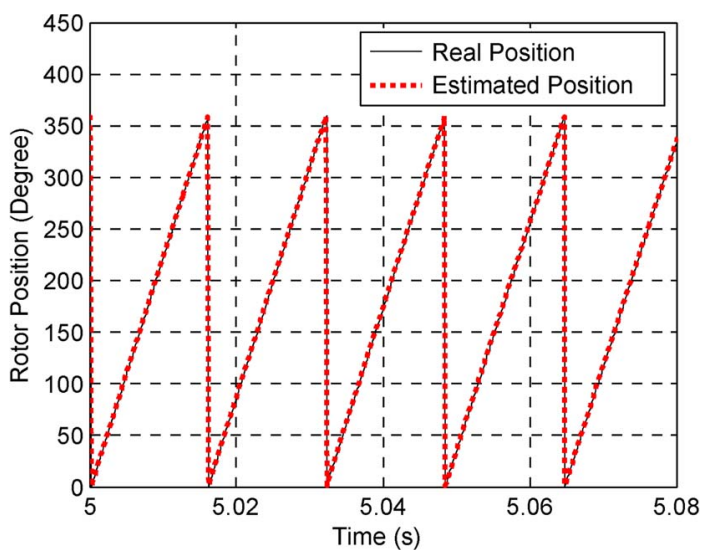

Fig. 23. Rotor position estimation during variable wind speed operation.

In a real PMG wind turbine system, the PMG will interface with load or power grid through power electronic converters, as shown in Fig. 1. The commanded instead of measured stator voltages will be used for rotor position and speed estimation, which is different from the three-phase resistive load setup in the experiments. When commanded voltages are used, appropriate compensation methods [20] might be needed to compensate for the nonlinear effects, e.g., deadtime effect, of the power electronic converters.

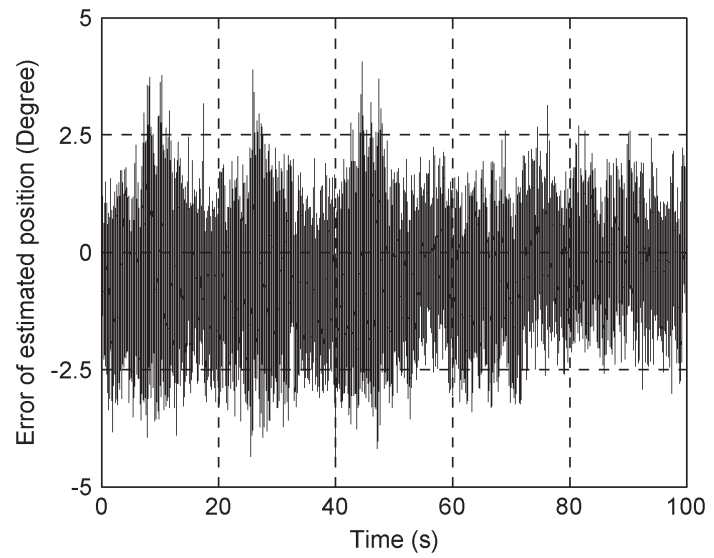

Fig. 24. Rotor position estimation errors.

\section{CONCLUSION}

This paper has proposed a novel mechanical sensorless control algorithm for maximum wind power generation using direct-drive PMG wind turbines. The values of wind speed, PMG rotor position and speed, and turbine shaft speed have been estimated from the measured ac currents (i.e., PMG stator currents) and the commanded (or measured) ac voltages of the MSC in real time. These estimated variables have been used for optimal control of the power electronic converters and the PMG. Therefore, the commonly used mechanical sensors in WTG systems, i.e., wind speed sensors and rotor position sensors, are not needed. The effectiveness of the proposed estimation methods and sensorless control algorithm has been demonstrated by simulation results of a 3-kW PMG wind turbine. Experimental studies have been carried out on a $300-\mathrm{W}$ practical PMG wind turbine, and the results have further validated the proposed position and speed estimation algorithms.

\section{REFERENCES}

[1] W. Qiao, L. Qu, and R. G. Harley, "Control of IPM synchronous generator for maximum wind power generation considering magnetic saturation," IEEE Trans. Ind. Appl., vol. 45, no. 3, pp. 1095-1105, May/Jun. 2009.

[2] Y. Chen, P. Pillay, and A. Khan, "PM wind generator topologies," IEEE Trans. Ind. Appl., vol. 41, no. 6, pp. 1619-1626, Nov./Dec. 2005.

[3] J. Ribrant and L. M. Bertling, "Survey of failures in wind power systems with focus on Swedish wind power plants during 1997-2005," IEEE Trans. Energy Convers., vol. 22, no. 1, pp. 167-173, Mar. 2007.

[4] W. Qiao, W. Zhou, J. M. Aller, and R. G. Harley, "Wind speed estimation based sensorless output maximization control for a wind turbine driving a DFIG," IEEE Trans. Power Electron., vol. 23, no. 3, pp. 1156-1169, May 2008.

[5] B. Boukhezzar and H. Siguerdidjane, "Nonlinear control of variable speed wind turbines without wind speed measurement," in Proc. 44th IEEE Conf. Decision Control, Seville, Spain, Dec. 12-15, 2005, pp. 3456-3461.

[6] T. Tanaka and T. Toumiya, "Output control by Hill-Climbing method for a small wind power generating system," Renew. Energy, vol. 12, no. 4, pp. 387-400, 1997.

[7] M. G. Simoes, B. K. Bose, and R. J. Spiegel, "Fuzzy logic based intelligent control of a variable speed cage machine wind generation system," IEEE Trans. Power Electron., vol. 12, no. 1, pp. 87-95, Jul./Aug. 1997.

[8] Q. Wang and L. Chang, "An intelligent maximum power extraction algorithm for inverter-based variable speed wind turbine systems," IEEE Trans. Power Electron., vol. 19, no. 5, pp. 1242-1249, Sep. 2004.

[9] K. Tan and S. Islam, "Optimal control strategies in energy conversion of PMSG wind turbine system without mechanical sensors," IEEE Trans. Energy Convers., vol. 19, no. 2, pp. 392-399, Jun. 2004.

[10] S. Chi and L. Xu, "Position sensorless control of PMSM based on a novel sliding mode observer over wide speed range," in Proc. 5th Int. Power Electron. Motion Control Conf., Aug. 14-16, 2006, pp. 1-7. 
[11] J. Seok, J. Lee, and D. Lee, "Sensorless speed control of nonsalient permanent-magnet synchronous motor using rotor-position-racking PI controller," IEEE Trans. Ind. Electron., vol. 53, no. 2, pp. 399-405, Apr. 2006.

[12] P. M. Anderson and A. Bose, "Stability simulation of wind turbine systems," IEEE Trans. Power App. Syst., vol. PAS-102, no. 12, pp. 37913795, Dec. 1983.

[13] N. Urasaki, T. Senjyu, and K. Uezato, "Investigation of influences of various losses on electromagnetic torque for surface-mounted permanent magnet synchronous motors," IEEE Trans. Power Electron., vol. 18, no. 1, pp. 131-139, Jan. 2003.

[14] A. Grauers, "Efficiency of three wind energy generator systems," IEEE Trans. Energy Convers., vol. 11, no. 3, pp. 650-657, Sep. 1996.

[15] S. J. Chapman, Electric Machinery Fundamentals, 4th ed. New York: McGraw-Hill, 2005.

[16] K. Kang, J. Kim, K. Hwang, and K. Kim, "Sensorless control of PMSM in high speed range with iterative sliding mode observer," in Proc. IEEE Appl. Power Electron. Conf. Expo., 2004, vol. 2, pp. 1111-1116.

[17] M. N. Marwali and A. Keyhani, "A comparative study of rotor flux based MRAS and back EMF based MRAS speed estimators for speed sensorless vector control of induction machines," in Conf. Rec. 32nd IEEE IAS Annu. Meeting, 1997, pp. 160-166.

[18] C. Li and M. Elbuluk, "A sliding mode observer for sensorless control of permanent magnet synchronous motors," in Conf. Rec. 36th IEEE IAS Апnи. Meeting, 2001, pp. 1273-1278.

[19] F. Z. Peng and T. Fukao, "Robust speed identification for speed sensorless vector control of induction motors," IEEE Trans. Ind. Appl., vol. 30, no. 5, pp. 1234-1240, Sep./Oct. 1994.

[20] H. Zhao, Q. M. J. Wu, and A. Kawamura, "An accurate approach of nonlinearity compensation for VSI inverter output voltage," IEEE Trans. Power Electron., vol. 19, no. 4, pp. 1029-1035, Jul. 2004.

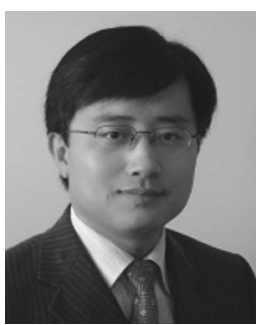

Wei Qiao (S'05-M'08) received the B.Eng. and M.Eng. degrees in electrical engineering from Zhejiang University, Hangzhou, China, in 1997 and 2002, respectively, the M.S. degree in highperformance computation for engineered systems from Singapore-MIT Alliance, Singapore, in 2003, and the Ph.D. degree in electrical engineering from Georgia Institute of Technology, Atlanta, in 2008.

From 1997 to 1999, he was an Electrical Engineer with China Petroleum \& Chemical Corporation (Sinopec). Currently, he is the Harold and Esther Edgerton Assistant Professor with the Department of Electrical Engineering at the University of Nebraska-Lincoln (UNL). His research interests include renewable energy systems, smart grids, power system control and optimization, condition monitoring and fault diagnosis, energy storage systems, power electronics, electric machines and drives, and computational intelligence for electric power and energy systems. He is the author or coauthor of three book chapters and more than 70 papers in refereed journals and international conference proceedings. $\mathrm{He}$ is an Associate Editor of the IEEE TRANSACTIONS ON Industry APPLICATIONS, the Chair of the Technical Thrust of Sustainable Energy Sources of the IEEE Power Electronics Society, and the Chair of the Task Force on Intelligent Control for Wind Plants of the IEEE Power \& Energy Society. He is the Technical Program Cochair of the 2012 IEEE Symposium on Power Electronics and Machines in Wind Applications (PEMWA 2012) and was the Technical Program Cochair and Finance Cochair of PEMWA 2009.

Dr. Qiao was the recipient of a 2010 National Science Foundation CAREER Award, the 2010 IEEE Industry Applications Society Andrew W. Smith Outstanding Young Member Award, the 2011 UNL Harold and Esther Edgerton Junior Faculty Award, and the 2011 UNL College of Engineering Edgerton Innovation Award.

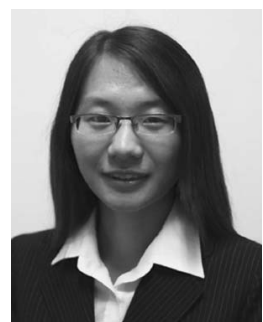

Xu Yang (S'07) received the B.S. degree in electrical engineering from Wuhan University, Wuhan, China, in 2007, and the M.S. degree in electrical engineering from the Polytechnic Institute of New York University, Brooklyn, NY, in 2009. Currently, she is working toward the Ph.D. degree in the Department of Electrical Engineering at the University of NebraskaLincoln.

She worked as a Developmental Intern at the New York Power Authority in 2009 and as a Graduate Student Intern at Phoenix International-a John Deere Company in 2011. Her research interests include control of wind energy conversion systems, electric motors and drives, electric machine design, applications of power electronics, power system operation and control, and renewable energy systems.

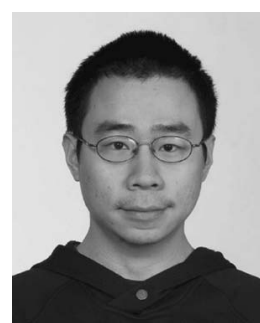

Xiang Gong (S'09) received the B.Eng. degree in electrical engineering from Huazhong University of Science and Technology, Wuhan, China, in 2006, and the M.Eng. degree in electrical engineering from Zhejiang University, Hangzhou, China, in 2008. Currently, he is working toward the Ph.D. degree in the Department of Electrical Engineering at the University of Nebraska-Lincoln.

His research interests include renewable energy systems, power electronics, and condition monitoring and fault detection for wind energy systems. 